\title{
Erratum to: International academy of agricultural and biosystems engineering (iAABE): a new instrument for recognizing the top profession
}

\author{
Da-Wen Sun ${ }^{1}$
}

Published online: 10 April 2017

(c) The International Society of Paddy and Water Environment Engineering and Springer Japan 2017

\section{Erratum to: Paddy Water Environ}

\section{DOI 10.1007/s10333-017-0586-y}

In the original publication of this article, the corresponding author name has been mentioned incorrectly. The correct name is provided in this erratum.

The online version of the original article can be found under doi:10.1007/s10333-017-0586-y.

\footnotetext{
Da-Wen Sun

dawen.sun@ucd.ie; masumoto@affrc.go.jp

1 National University of Ireland-Dublin, University College

Dublin, Dublin, Ireland
} 